\title{
LA JURIDIZACIÓN JUDICIAL DE LA SALUD EN RELACIÓN AL CANNABIS. ANÁLISIS DE FALLOS ESPAÑOLES DE TRIBUNALES SUPERIORES
}

\author{
ELVIO GALATI* \\ Doctor en Derecho por la Universidad Nacional de Rosario (Argentina) \\ Investigador científico $1 \mathrm{~b}$ de la Universidad Abierta Interamericana (UAI) \\ elviogalati@gmail.com
}

\begin{abstract}
RESUMEN: El trabajo analiza algunos fallos españoles del Tribunal Supremo y del Tribunal Constitucional referidos al cannabis para dar cuenta del grado de juridización de la salud presente en ellos. También se los analiza desde la Teoría General del Derecho, para comprobar si elaboran o aplican normas. Y se relacionan estos dos aspectos: la juridización y el funcionamiento de las normas. En la Medicina la medicalización y en el Derecho la juridización implican la intervención indebida de una disciplina, transformando situaciones de la vida cotidiana o factores de riesgo en enfermedades o en delitos o ilicitudes, respectivamente. La juridización es judicial cuando quienes intervienen indebidamente son los jueces. La juridización puede ser baja, media o alta, según la intensidad de la intervención, que es valorada negativamente, si la justicia es la libertad del individuo para que, según su cosmovisión, desarrolle su personalidad. La metodología es cualitativa y cuantitativa, en tanto, por un lado, aúna el rigor numérico de la regularidad, y la comprobación empírica de las afirmaciones y, por el otro, comprende el sentido -interpretación- de las conductas apreciadas a través del estudio de casos. Se concluye provisoriamente en la juridización a nivel de los tribunales superiores españoles.
\end{abstract}

PALABRAS CLAVE: juridización, medicalización, complejidad, trialismo, cannabis, derecho de la salud, bioética.

ABSTRACT: The paper analyzes some Spanish judgements of the Supreme Court and the Constitutional Court as regards cannabis to account for the degree of juridization of health included in them. They are also analyzed from the General Theory of Law, to check whether they elaborate or apply rules. And these two aspects are related: the juridization and the operation of the rules. In medicine, medicalization, and in law, juridization imply the improper intervention of a discipline, transforming situations of everyday life or risk factors into diseases, or into crimes or illegality, respectively. Juridization is judicial when those who are inappropriately involved are judges. The juridization can be low, medium or high, depending on the intensity of the intervention, which is negatively assessed, if justice is the freedom of the individual so that, according to their worldview, individuals can develop their personality. The methodology is qualitative and quantitative because, on the one hand, it combines the numerical rigor of regularity and the empirical verification of the statements and, on the other hand, it comprises the sense interpretation- of the behaviors appreciated through the study of cases. It is provisionally concluded in the judicial juridization at the level of the Spanish superior courts.

KEYWORDS: juridization, medicalization, complexity, trialism, cannabis, health law, bioethics.

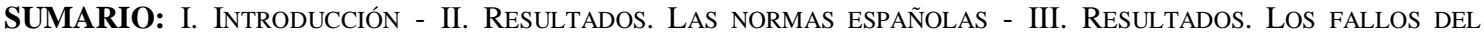
Tribunal SupRemo y DEl Tribunal CONSTituCiONAL ESPAÑOL - III.1 Fallos del Tribunal Supremo - III.2 Fallos del Tribunal Constitucional - IV. DisCuSIÓN. JURIDIZACIÓN DE LA SALUD - V. CONCLUSIÓN - VI. BIBLIOGRAFÍA. 


\section{INTRODUCCIÓN}

El objetivo de este trabajo es analizar fallos del Tribunal Supremo y del Tribunal Constitucional españoles a la luz de la teoría de la medicalización de la vida y la juridización de la salud. Específicamente se apunta a calificarlos en función del grado de juridicidad que presentan. Y también se apunta a encuadrar dichos fallos desde la Teoría General del Derecho (TGD) para establecer cuántos aplican, y cuántos elaboran o crean normas.

Los marcos teóricos de este trabajo son el pensamiento complejo de Edgar Morin, y la teoría trialista del mundo jurídico, en su versión actualizada del "pensamiento jurídico complejo". . El pensamiento complejo hace referencia a: la contradicción, la unitas multiplex ${ }^{2}$, la existencia de distintas lógicas, la insuficiencia de la razón, la jerarquización de la singularidad, el sistema y las distintas interrelaciones que, como emergentes y restricciones pueden darse en él. La diversidad está al interior de la complejidad, en tanto "[...] es [...] un tejido de constituyentes heterogéneos inseparablemente asociados, que presentan la paradójica relación de lo uno y lo múltiple"3. La complejidad asocia los pensamientos que clásicamente pueden excluirse, los llama a conciliar, oscilar, competir y antagonizar, muestra las partes y el todo, la necesidad de la incertidumbre, la unión de los juicios de hechos y valor, de la ciencia y la filosofía, contempla el papel del investigador, abarca la perspectiva de lo global y lo local, y la visión sistémica del todo en relación con las partes.

Por otro lado, Werner Goldschmidt, creador de "la teoría trialista del mundo jurídico considera que el Derecho es el conjunto de los repartos, captados por las normas y valorados, ambos, por la justicia" 4 . Cuando hablamos de la categoría trialista de "elaboración" de una norma, significa que hay ausencia de norma jurídica escrita, de ley, y estamos ante una carencia histórica. También una norma puede ser dejada de lado porque el tribunal tiene un distinto criterio de justicia que el legislador, y entonces se habla de una carencia dikelógica. Es común que se oculte dicha tarea elaboradora tras la interpretación, cuando en realidad interpreta quien sigue una voluntad, la del legislador, sea la que sea.

La medicalización de la vida señala que la Medicina transforma situaciones de la vida cotidiana o meros factores de riesgo en enfermedades, priorizando la venta de terapias o medicamentos, en lugar de la salud de las personas. El origen de este término puede encontrarse en Iván Illich, quien escribió Némesis médica. La expropiación de la salud ${ }^{5}$, justamente porque

(*) Posdoctor en Derecho por la Universidad de Buenos Aires (Argentina) y Doctor en Derecho por la Universidad Nacional de Rosario (Argentina). Investigador científico 1b de la Universidad Abierta Interamericana (UAI). Becario del Programa de Movilidad Docente a Madrid 2017, en la Universidad de Valladolid, España. Categoría 2 del Programa de Incentivo a docentes-investigadores del Ministerio de Educación de la Nación. elviogalati@gmail.com www.elvioacademia.wordpress.com

${ }^{1}$ V. GALATI, E., "Introducción al pensamiento jurídico complejo. La teoría trialista del mundo jurídico y el pensamiento complejo de Edgar Morin", en "Revista de la Facultad de Derecho", n²0, Rosario, UNR, 2012, págs. 157-215.

2 “[...] paradigma que asociaría lo uno y lo diverso en una concepción fundamental de la unitas multiplex. [...] un paradigma, que en lugar de separar la idea de unidad y la de diversidad, y de oponerlas, las uniría". MORIN, E., y PIATELLI-PALMARINI, M. "La unidad del hombre como fundamento y aproximación interdisciplinaria", en AAVV, "Interdisciplinariedad y Ciencias Humanas", trad. de Jesús Gabriel Pérez Martín, Madrid, Tecnos, 1983, pág. 191.

${ }^{3}$ MORIN, CIURANA, R., y MOTTA, R., "Educar en la era planetaria. El pensamiento complejo como método de aprendizaje en el error y la incertidumbre humana", Valladolid, UNESCO - Univ. de Valladolid, 2002, pág. 40.

${ }^{4}$ GALATI, "Los comités hospitalarios de bioética. Una comprensión trialista y transdisciplinaria desde el Derecho de la Salud", Ciudad Autónoma de Buenos Aires, Teseo-Universidad Abierta Interamericana, 2015, https://elvioacademia.files.wordpress.com/2016/11/galati-los-comitc3a9s-hospitalarios-de-bioc3a9tica-

transdisciplinariedad.pdf (23.3.2018), pág. 35 .

${ }^{5}$ Barcelona, Barral, 1975. 
la medicalización apunta a "[...] expropiar el poder del individuo para curarse a sí mismo y para modelar su ambiente" ${ }^{\prime 6}$. En el ámbito de las drogas, pueden pensarse tres modelos ${ }^{7}$. El del prohibicionismo, el terapéutico y la reducción de daños. Los dos primeros presentan el ideal de una sociedad exenta de drogas y son por lo tanto medicalizadores. Por su parte, el modelo de reducción de daños, plantea el aprovechamiento de estrategias orientadas a la minimización de las consecuencias negativas asociadas a ciertas prácticas de uso ${ }^{8}$. Y la juridización de la salud surgió a raíz de la extensión analógica del concepto de la medicalización de la vida al ámbito del Derecho pensando que también hay situaciones que no son susceptibles de ser tratadas jurídicamente, a pesar de lo cual el Derecho se entromete de todas formas, indebidamente ${ }^{9}$. En el caso del cannabis, se lo medicaliza si se trata su consumo como una enfermedad, y se lo juridiza cuando, por ejemplo, el consumidor es tratado como un delincuente ${ }^{10}$. Así, "[...] las drogas se asocian directamente a la 'delincuencia' [...]"11.

La juridización puede ser alta, media e intensa en función del grado e impacto de la intervención. Y puede ser originaria o derivada según que el Derecho intervenga con o sin previa medicalización, respectivamente. También puede ser legislativa, judicial, administrativa, según qué aspecto del Derecho intervenga en función del lugar del Estado que provoca la juridización; y puede ser doctrinaria. Y si todos los estamentos estatales y académicos intervienen la juridización es total. Si hay juridización, medicalización y clericalización, es decir, en este último caso, cuando la Iglesia (católica) interviene indebidamente, habrá sistemización de la vida, en tanto la libertad del individuo peligra seriamente. Una consecuencia

\footnotetext{
${ }^{6}$ ILLICH, op. cit., pág. 9.

${ }^{7}$ Algunos hablan de ruptura paradigmática. CARRIER, N., y QUIRION, B., "Les logiques de contrôle de l'usage des drogues illicites : La réduction des méfaits et l'efficience du langage de la péllirisation", en "Drogues, santé et société”, vol. 2, nº1, Montréal, 2003, pág. 9. En efecto, según las características que Thomas Kuhn asigna al paradigma, una misma sustancia, que siempre ha sido igual, por unos es tomada como algo malo y por otros como algo neutro. La calificación cambia según la posición ideológica del hablante. Sobre el tema p. v. GALATI, "Visión compleja de los paradigmas científicos y la interpersonalidad en la ciencia", en "Cinta de Moebio. Revista de Epistemología de Ciencias Sociales", nº44, Santiago, Fac. de Cs. Sociales, Univ. de Chile, 2012, págs. 122-145, en http://www2.facso.uchile.cl/publicaciones/moebio/44/galati.html (26.9.2012).

${ }^{8}$ CARRIER y QUIRION, op. cit., pág. 6. "La medicina y su práctica clínica comienzan a ocupar un lugar central en los dispositivos de control que se implementan en la sociedad". INCHAURRAGA, S., y MANERO, E., "Políticas de drogas, alteridades y construcción de la ciudadanía en Argentina contemporánea", en "Outros Tempos", vol. 14, n²4, 2017, pág. 209.

${ }^{9}$ Sobre el tema p. v. GALATI, "La eutanasia y la medicalización de la muerte desde una perspectiva jurídica compleja", en "Revista Latinoamericana de Bioética", vol. 18, n³4-1, Bogotá, Universidad Militar de Nueva Granada, 2018, págs. 68-86; GALATI, "Redefiniendo la salud y el amparo a raíz de la cobertura judicial de la fertilización asistida y a la luz de la medicalización de la vida", en "Revista de Derecho de Familia y de las Personas”, año VIII, n5, 2015, Bs. As., La Ley, págs. 191-202.

10 "Estigmatizados y excluidos, los 'drogadictos' son considerados ante todo enfermos y delincuentes". INCHAURRAGA, y MANERO, op. cit., pág. 209. "[...] el Estado se inmiscuye en la intimidad de las personas que consumen drogas castigándoles con condenas a prisión u obligándoles a rehabilitarse”. Íd., pág. 212. Como muy bien señalan los autores, el enfoque es más puesto en la seguridad pública que en la salud. Íd., pág. 215. De ahí la importancia de diferenciar el Derecho Penal del Derecho de la Salud, dando primacía siempre a la salud. Sobre el tema p. v. GALATI, "Epistemología compleja del Derecho de la Salud", 2018, inédito.

${ }^{11}$ LÓPEZ BETANCOURT, E., "Drogas, entre el derecho y el drama", Madrid, Centro de Estudios Ramón Aceres, 2011, pág. 201. "[...] sirve como herramienta política, pues se convierte automáticamente, en el culpable de todos los males sociales [...] un hábito exclusivo de quienes se dedican a infringir la ley”. Íd., pág. 202.
} 
de la juridización es el despilfarro de recursos, en tanto la intervención indebida genera gastos ${ }^{12}$. Un ejemplo se ve en los tribunales abarrotados de causas de pequeños consumidores ${ }^{13}$.

El cannabis es una droga en tanto es una sustancia cuyo consumo produce una modificación de una función ${ }^{14}$, en este caso, del sistema nervioso central.

[...] término genérico empleado para designar los diversos preparados psicoactivos de la planta de la marihuana (cáñamo), Cannabis sativa. Estos preparados son: hojas de marihuana (en la jerga de la calle: hierba, maría, porro, canuto...), bhang, ganja o hachís (derivado de la resina de los ápices florales de la planta) y aceite de hachis ${ }^{15}$.

Si se toma la definición de droga de la OMS se podrá observar su riqueza:

En medicina se refiere a toda sustancia con potencial para prevenir o curar una enfermedad o aumentar la salud física o mental y en farmacología como toda sustancia química que modifica los procesos fisiológicos y bioquímicos de los tejidos o los organismos ${ }^{16}$.

El cannabis puede ser visto entonces como fuente de salud, como fuente de modificaciones en el organismo humano y, por supuesto, en algunos casos, como nocivo. Esto nos lleva a decir que una aspirina y la heroína son ambas drogas. Lo cual señala también la OMS: “[...] la cafeína, el tabaco, el alcohol y otras sustancias utilizadas a menudo con fines no médicos son también drogas en el sentido de que se toman, al menos en parte, por sus efectos psicoactivos"17. De ahí que sea difícil poder hablar de "drogas" como un conjunto uniforme, estable y preciso de sustancias.

La metodología de trabajo es empírica, en tanto se analizan 13 fallos del Tribunal Supremo y 2 fallos del Tribunal Constitucional, máximas instancias españolas. Como la investigación está en curso, se acercan resultados parciales. Los fallos analizados van desde el 2007 a 2017.

12 “[...] qué tanto gasto de recursos representa para la colectividad, hacer que las personas no consuman drogas, frente al posible despilfarro que acarrea el consumo". Íd., pág. 197. Al contrario, "[...] es factible que una iniciativa a favor de la legalización se acompañe de un esquema tributario, que representaría nuevos ingresos en favor del Estado, canalizables a la misma política preventiva y sanitaria en materia de drogas”. Íd., pág. 199. Como debería ocurrir con el juego, el alcohol y el tabaco.

13 “[...] las estadísticas carcelarias en Ecuador durante los años de cooperación activa con las políticas de drogas de los Estados Unidos, muestran que la mayoría de los detenidos por delitos de drogas pertenecen a los sectores más vulnerables y marginalizados de la sociedad: consumidores con problemas de drogas, personas pobres y mujeres". MANJÓN-CABEZA OLMEDA, A., "La solución. La legalización de las drogas", Barcelona, Random House Mondadori, 2012, pág. 234. "El músico Andrés Calamaro manifestó en un recital en la ciudad de La Plata "qué linda noche para fumarse un porrito' en alusión a su tema 'Loco' y tuvo por ello una causa por apología del consumo". INCHAURRAGA, "Marihuana; el argumento más débil de la teoría prohibicionista", en AAVV, "Las drogas: entre el fracaso y los daños de la prohibición. Nuevas perspectivas en el debate despenalización/legalización", comp. por Silvia Inchaurraga, Rosario, Centro de Estudios Avanzados en Drogadependencias y SIDA, Asoc. de Reducción de Daños de la Argentina, 2003, pág. 203.

${ }^{14}$ PADILLA ALBA, H., "La problemática de legalizar el cannabis en España", Córdoba, Universidad de Córdoba, 2011, pág. 9. "En medicina se refiere a toda sustancia con potencial para prevenir o curar una enfermedad o aumentar la salud física o mental y en farmacología como toda sustancia química que modifica los procesos fisiológicos y bioquímicos de los tejidos o los organismos". ORGANIZACIÓN MUNDIAL DE LA SALUD, "Glosario de términos de alcohol y drogas", Madrid, OMS y Gobierno de España, 1994, pág. 33.

15 Íd., pág. 22.

16 Íd., pág. 33.

${ }^{17}$ Íd. 


\section{RESULTADOS. LAS NORMAS ESPAÑOLAS}

El Código Penal ${ }^{18}$ (CP) sanciona la producción y distribución de drogas en el art. 368, aunque no el consumo, pero sí el autocultivo. No se permite al consumidor obtener la sustancia de manera legal ${ }^{19}$. Lo que hay que relacionar con el escaso monto y las circunstancias personales del involucrado.

Los que ejecuten actos de cultivo, elaboración o tráfico, o de otro modo promuevan, favorezcan o faciliten el consumo ilegal de drogas tóxicas, estupefacientes o sustancias psicotrópicas, o las posean con aquellos fines, serán castigados con las penas de prisión de tres a seis años y multa del tanto al triplo del valor de la droga objeto del delito si se tratare de sustancias o productos que causen grave daño a la salud, y de prisión de uno a tres años y multa del tanto al duplo en los demás casos. No obstante lo dispuesto en el párrafo anterior, los tribunales podrán imponer la pena inferior en grado a las señaladas en atención a la escasa entidad del hecho y a las circunstancias personales del culpable. No se podrá hacer uso de esta facultad si concurriere alguna de las circunstancias a que se hace referencia en los artículos 369 bis y 370 .

Si bien no se puede penar el consumo, sí se penalizan conductas accesorias, afines o que se encuentran en sus alrededores, como el cultivo, la elaboración, la facilitación del consumo, o la posesión. Todo lo cual indica que se penaliza un acto personal, como es todo aquello que esté encaminado al consumo.

También es importante destacar que el Código hace hincapié en el grave daño a la salud. ¿Qué pasa con aquellas sustancias que no lo causan entonces? ¿Por qué son penalizadas sus conductas? ¿Qué es la escasa entidad del hecho? Si es escasa, ¿por qué entonces se lo penaliza? ¿En qué influyen las circunstancias personales del culpable? ¿Por qué se culpabiliza a alguien por consumir drogas? Todo lo cual va hablando de la existencia de juridización legislativa ${ }^{20}$.

Una constante en la política criminal es la tipificación del delito vinculado a la marihuana como de peligro abstracto, en tanto se sancionan conductas capaces de crear un riesgo para el bien jurídico en cuestión, en este caso la salud, pero sin requerirse la producción de un daño concreto e individualizado ${ }^{21}$. Es decir, hay "[...] mera posibilidad de la lesión",22. Cabe preguntarse qué es lo que se destruye ${ }^{23}$ aquí, teniendo en referencia al individuo que solo posee la marihuana para su consumo personal, o la actitud de los miembros de un club cannábico que almacenan la marihuana para su posterior consumo en un local. Volviendo al

\footnotetext{
${ }^{18}$ La prohibición comenzó en 1971 cuando se generó un tipo penal autónomo que castigaba el cultivo, fabricación, elaboración, transporte, tenencia, venta, donación o tráfico de drogas tóxicas o estupefacientes, armonizando con los estándares de la Convención Única. LEARY, W. E., "Marijuana. Aspectos sociales, jurídicos y económicos de la obtención de enteógenos cannabinoides y alternativas a la actual política criminal en España”, Londres, Amazon, 2012, págs. 65-66.

${ }^{19}$ MUÑOZ SÁNCHEZ, J., "Política criminal de drogas. Reflexiones en torno a la normalización del cannabis", en AAVV, "Hablemos del cannabis. Avances en drogodependencias", ed. por L. Pantoja, Bilbao, Universidad de Deusto, 2007, pág. 37.

${ }^{20}$ Aunque no siempre fue así en España, en tanto por la reforma de la LO 8/1983 solo era punible la posesión con el fin de traficar. PADILLA ALBA, op. cit., pág. 23. Sí fueron importantes las agravantes: si se difunde la droga entre menores de 18 años de edad, si se difunde la droga en ciertos lugares como centros docentes, unidades militares o establecimientos penitenciarios, si el que comete el acto pertenece a una organización que difunde, o la importante cantidad de droga para traficar. Íd., págs. 23-24.

${ }^{21}$ LEARY, op. cit., págs. 70-71.

${ }^{22}$ SOLER, S., "Derecho Penal Argentino”, t. 2, actualizado por Guillermo Fierro, Bs. As., TEA, 1992, pág. 196.

${ }^{23}$ Íd.
} 
daño, el delito consiste en la efectiva lesión al bien jurídico que se protege ${ }^{24}$. Si se castiga la tenencia o portación de arma de guerra, para proteger con un delito de peligro concreto a la vida como bien jurídico, que es también protegido por el delito de homicidio, que es un delito de daño; ¿no podría protegerse a la salud pública con un delito de peligro si el delito de daño concreto es el tráfico de estupefacientes? Siendo aquí el delito de peligro concreto la tenencia del estupefaciente. ¿Acaso alguien no podría decir que la tenencia de un arma de guerra forma parte de su intimidad? Es evidente, a los fines de la comparación, que un cigarrillo de marihuana no tiene la misma potencialidad de producir daño que un arma de guerra. Vemos cómo ayuda para analizar la justicia de una solución el método de las variaciones ${ }^{25}$. Además, sí es más peligroso un cigarrillo de tabaco que uno de marihuana, debido a los efectos terapéuticos y recreativos del cannabis. Se pone en evidencia entonces lo que Soler llama la doble coraza de protección $^{26}$, en nuestro caso, defendiéndose la salud pública del tráfico de la sustancia ilícita, y de la existencia de la sustancia ilícita, que si bien no es traficada, al existir, proviene de algún sitio. En la misma línea de Soler, un delito de peligro abstracto en nuestro ámbito sería el de la apología de la "droga", en tanto aquí se ve "[...] una idoneidad genérica para crear peligros y causar daños" $"$. No hay un verdadero peligro, sino la posibilidad de peligro ${ }^{28}$. La técnica penal parece bien aplicada en lo relativo al bien jurídico salud, aunque los reparos vienen de la mano de la intimidad o privacidad en la que el Estado se inmiscuye. Tomando otra conceptualización de los delitos de peligro, se explica que hay en ellos incertidumbre ${ }^{29}$, en tanto si bien puede haber ejercicio de la privacidad e intimidad en la conducta de quien consume marihuana, incluso cocaína, ella viene de un lugar incierto, ya que su comercio es clandestino, hoy en los dos casos. Y si hay tráfico clandestino, es porque el Estado lo considera dañoso. En suma, todo depende de la caracterización de la cosa como perjudicial. Y sabemos que ello no ocurre en la marihuana. Sí en la cocaína, aunque aquí cabe preguntarse si el individuo puede dañarse. Contestando que sí, no todos quieren dañarse. Y podría no ser auspicioso que una sustancia "peligrosa" circule sin restricción alguna. Pero ello nos llama a colocar la figura en el ámbito de la contravención, con otro tipo de sanciones administrativas.

Habiendo constatado la juridización legislativa, en tanto el Estado se inmiscuye indebidamente en la esfera de intimidad del individuo que consume cannabis, cabe analizar ahora el papel de los jueces, que son frecuentemente recurridos en el ámbito español para juzgar dichas conductas.

\section{RESULTADOS. LOS FALLOS DEL TRIBUNAL SUPREMO Y DEL TRIBUNAL CONSTITUCIONAL ESPAÑOL}

¿Por qué es importante tener en cuenta las sentencias? En este caso, de los tribunales españoles. Si bien resuelven importantes temas de la vida cotidiana de las personas, no dejan de

\footnotetext{
${ }^{24}$ Ibídem.

${ }^{25}$ Este método consiste en que se varía mentalmente el caso real mediante modificaciones irreales, a fin de averiguar cuáles circunstancias son dikelógicamente importantes y en qué se cifra esta importancia. GOLDSCHMIDT, W., "Introducción filosófica al Derecho. La teoría trialista del mundo jurídico y sus horizontes", 6 a ed., Bs. As., Depalma, 1987, pág. 397.

${ }^{26}$ SOLER, op. cit., t. 2, pág. 197.

${ }^{27}$ Íd.

${ }^{28}$ ZAFFARONI, E., "Manual de Derecho Penal. Parte General”, 6ª ed., Bs. As., Ediar, 1997, pág. 474. El autor critica esta distinción y propone que en realidad, en el peligro abstracto quien prueba es el que acusa, y en los delitos de peligro concreto quien prueba es el acusado, girando todo alrededor de la carga de la prueba.

${ }^{29}$ Íd.
} 
ser también humanos. La propia doctrina ibérica lo señala: "[...] los magistrados, como cualquier persona, también poseen 'procesos de categorización, estereotipación, actitudes, motivaciones y prejuicios que, de alguna manera, aparecerán en ese discurso jurídico y que influyen en el resultado final de la sentencia" ${ }^{30}$. Recuérdese la "premisa mayor inarticulada" de la que hablaba Oliver Holmes: [...] an inarticulate and unconscious judgement [...] You can give any conclusion a logical form ${ }^{31}$.

Además, es posible sistematizar los fallos en función de un criterio determinado, que lo establecerá el organizador en cuestión, pero que es posible de establecer para configurar lo que se llama jurisprudencia, que es la costumbre judicial ${ }^{32}$, es decir, un conjunto de fallos, emitidos por tribunales determinados, siguiendo una misma solución, para un problema también determinado, por un conjunto de factores similares, que pueden agruparse, más allá de las características particulares de los casos en cuestión. Como costumbre, la jurisprudencia “[...] es un fenómeno que trata de construir lo jurídico desde las bases mismas de lo real, ya que un reparto reputado ejemplar, es decir, digno de ser repetido, es analizado por los hombres y, al ser juzgado 'ejemplar', es imitado a través del esquema modelo-seguimiento" ${ }^{33}$. En el caso de las sentencias españolas, veremos cómo el análisis de un caso tras otro nos obliga, en aras de mantener la misma solución para todos, a diferenciar grupos de casos.

La jurisprudencia soluciona también conflictos jurídicos, y es en este sentido una fuente del derecho. No por su particularidad es menos importante, si se piensa que la ley vive en el mundo de la idealidad sin contacto con la realidad jurídica hasta que se aplica para la solución de un caso concreto, porque es para ello que se ha creado, para el caso en que alguien no la cumpla.

La fuerza que el precedente tiene de por sí sería mayor en el caso de España de prosperar un proyecto de ley para dar fuerza vinculante al precedente del Tribunal Supremo, a los fines de unificar jurisprudencia cuando algún fallo contradiga su doctrina ${ }^{34}$. Incluso parte de los juristas españoles le dan fuerza vinculante a las decisiones del Tribunal Constitucional ${ }^{35}$. Hay que tener en cuenta que el valor vinculante del precedente deriva de la propia práctica judicial en la que él consiste, es decir, no está atado a la ley, en tanto es una conducta colectiva que los hombres del Poder Judicial siguen por mero hábito, en el sentido de constituir la materialidad de una situación fáctica, en tanto la ley pertenece a una región ideal enunciativa, que intensificando el análisis realista, hace que la ley misma se convierta en una mera directriz ${ }^{36}$ en tanto existe si es reconocida, interpretada y aplicada por jueces o cualquier funcionario.

\footnotetext{
${ }^{30}$ ARANA, X., "Drogas, legislaciones y alternativas. De los discursos de las sentencias sobre el tráfico ilegal de drogas a la necesidad de políticas diferentes", Donostia/San Sebastián, Tercera Prensa, 2012, pág. 21.

${ }^{31}$ HOLMES, O., "The path of law", en "Harvard Law Review”, 10, 1897.

${ }^{32}$ Sobre la costumbre judicial y ejemplos de ellas p. verse GALATI, "La costumbre en el Derecho Argentino. Análisis jusfilosófico y trialista de la 'razón' del pueblo", Ciudad Autónoma de Buenos Aires, Teseo-Universidad Abierta Interamericana, 2015, https://elvioacademia.files.wordpress.com/2016/11/galati-la-costumbre-en-el-derechoargentino.pdf (23.3.2018).

${ }^{33}$ Íd., pág. 115.

${ }^{34}$ COUSO SALAS, J., "El uso de precedentes en materia penal: retórica y realidad en perspectiva", en "Revista General de Derecho Penal”, Madrid, Iustel, RI405151, pág. 3.

35 Íd., pág. 6. A diferencia de lo que ocurre con la Corte Suprema de Justicia de la Nación argentina, a la hora de decidir un recurso de inconstitucionalidad, el Tribunal Constitucional español llama a los involucrados en la ley cuestionada, por ejemplo, al presidente del Senado y al titular del Congreso de los Diputados, al Presidente del Gobierno, a quien represente a un parlamento autonómico, etc. Lo cual da a entender que se participa de una decisión importante a quienes son la "voz" del pueblo, si se pretende inaplicar una decisión suya a un caso concreto.

36 “"...] si las normas jurídicas fueran claras y precisas, o si las partes en una controversia se pusieran de acuerdo respecto de las normas relevantes, habría muy pocos litigios o ninguno". FRANK, J., "Una defensa de las escuelas de
} 
Como fallos sobre el cannabis hay muchos, el criterio de exclusión estuvo dado por la referencia principal de los casos a aspectos procesales o vinculados a garantías constitucionales, como el arresto, el testimonio, el secreto de las comunicaciones, la presunción de inocencia, las cuestiones probatorias, etc. Tampoco se busca hacer un tratamiento profundizado de casos involucrados en tráfico de marihuana y otras drogas. Mi idea apunta a analizar cómo trata el Estado al consumidor de drogas blandas, cómo valoran los tribunales cuestiones referidas a la marihuana, si se la considera algo contra la salud pública, es decir, ver si hay indicios de medicalización o juridización. A la vez que se analizará si el fallo en cuestión aplica o elabora normas. La franja temporal de las sentencias va desde 2007 hasta 2017, y se presenta un avance de la investigación.

\section{III.1 Fallos del Tribunal Supremo}

1) El 21.5.2008 la Sala 4 de lo Social del Tribunal Supremo se pronunció (rec. 528/2007) en el caso en donde la empresa Foresma SA despide en 2005 a Juan Miguel y el juzgado que primero intervino lo declaró procedente. La empresa estaba dedicada a la extinción de incendios forestales y otras emergencias. El trabajador fue sancionado con despido disciplinario, por el consumo de sustancias psicoactivas, derivados del cannabis, hachís o marihuana; lo que fue considerado incompatible con su labor por la necesidad de seguridad del conductor y de sus compañeros, capacidad para detectar y comunicar el peligro inherente también a todo incendio forestal. El sujeto era especialista helitransportado, es decir, transportaba en helicóptero ante posibles emergencias. Comunicó que consumía habitualmente marihuana, mientras conduce a su trabajo; situación que fue descripta como de comportamientos extraños en un grupo, con desapariciones, estados de humor, euforia, ojos rojos, descoordinación en el habla; situación que se repetía. Al realizarse una inspección, se detectaron dos plantas de marihuana. El implicado dijo que fumaba marihuana hasta que comenzaba su jornada laboral, pero nunca durante la misma. El fallo habla de los efectos del cannabis: trastornos en la coordinación, sensación de enlentecimiento del tiempo, alteración de la concentración, y en dosis altas, ansiedad, lentitud psicomotora, alteraciones de la memoria, desorientación, confusión cognitiva, alucinaciones. Y en abstinencia, apatía, poca motivación, irritabilidad, nerviosismo, ansiedad. En el tribunal superior, el despido fue declarado improcedente, ya que la comunicación debe concretar los días y estados en que se encontró al sujeto bajo la influencia del cannabis, para que el trabajador pueda defenderse. La empresa alega que un peón colocador de estructuras fue despedido porque fumaba porros después de comer, justo antes de trabajar y que ocasionalmente fumaba durante el trabajo. El trabajador se

abogados", en AAVV, "Enseñanza clínica del Derecho. Una alternativa a los métodos tradicionales de formación de abogados", coord. por Marta Villarroel y Christian Courtis, México DF, Instituto Tecnológico Autónomo de México, 2007 , pág. 65. 
El presente caso no es juridizador, en tanto habla de defectos formales como la imputación genérica y falta de precisión a la hora del despido. Si la precisión hubiera permitido ver si el bombero consumía durante el trabajo, para admitir el despido, la intervención del Estado se justifica, para evitar que alguien con la consciencia alterada manipule herramientas de trabajo peligrosas ${ }^{37}$.

Desde el punto de vista de la TGD, norma alguna prevé el caso del despido por causa de consumo de sustancias psicoactivas, lo que da lugar a una elaboración.

2) El 12.4.2007, la sala 2 del Tribunal Supremo se pronunció en el caso Jon (rec. 1667/2006), mayor de edad nacido en Marruecos que se encontraba en la calle ofreciendo hachís y éxtasis (MDMA). Siendo revisado por los policías, encontraron hachís en 12,867 kgs. y 43 pastillas de MDMA y 110 euros producto del tráfico de drogas. Y fue condenado por delito contra la salud pública de droga que causa grave daño. Se trata de una conducta que constituye una forma de difusión del consumo de drogas tóxicas. Menciona el principio de insignificancia, según el cual la cantidad de droga resulta incapaz de producir efecto nocivo alguno en la salud; y expresa las cantidades, variando en distintos pronunciamientos: 0,02grs., 0,03grs., 0,05grs., 0,06grs. de heroína, 0,10grs. de cocaína. El legislador no establece la posibilidad de renunciar a la punibilidad en casos de reducido daño social, ya que por la gravedad que le atribuye a los hechos, el peligro abstracto es suficiente para justificar su intervención. Cita sentencias en las que la nimiedad debe ser de aplicación excepcional y restrictiva, cuando la sustancia no constituya por sus efectos una droga tóxica. Según el informe del Instituto Nacional de Toxicología, para el MDMA son 20 miligramos o 0,02grs. En el caso se supera la dosis mínima (13,616 grs. de MDMA).

Este fallo no es juridizador, en tanto la intervención del Estado se justifica por el tráfico público, y la posibilidad de que se expanda el consumo a terceros no maduros o incapaces.

Desde el punto de vista de la TGD, hay aplicación de norma.

3) El 11.10.2010, la sala 2 del Tribunal Supremo se pronunció en el caso Mariano y Torcuato (rec. 397/2010), donde estaba involucrado un mayor de edad sin antecedentes penales que vendía cocaína y marihuana. La pena se atenúa por la adicción del vendedor en tratamiento de rehabilitación, en tanto el drogodependiente acredite haber finalizado con éxito un tratamiento de deshabituación, siempre que la cantidad de drogas tóxicas no fuere importante o grave. En el caso se encontraron 11,92grs. y 1.5 kgrs. de marihuana. Obtuvo así 1 año y 6 meses de prisión. Forzar la rehabilitación implica medicalizar y juridizar.

Desde el punto de vista de la TGD, hay aplicación de norma.

4) El 7.9.2015, la sala segunda de lo penal del Tribunal Supremo (rec. 1765/2014) se pronunció en el caso "Asociación de Estudios y Usuarios del Cáñamo EBERS". Se trata de un fallo pleno, dictado a raíz de un caso de cultivo y distribución organizada, institucionalizada y con vocación de persistencia en el tiempo de cannabis en un colectivo integrado por 290 personas que formaban una asociación, abierta a nuevas incorporaciones. El cultivo compartido de cannabis destinado al consumo exclusivo y excluyente de los miembros, aun siendo ilegal, puede ser penalmente irrelevante.

\footnotetext{
37 “[...] la penalización generalizada debiera ser sustituida por un esquema regulatorio que contemple ciertas restricciones directas y específicas, como la prohibición de usar vehículos bajo el influjo de bebidas alcohólicas, o la de fumar en lugares públicos cerrados”. LÓPEZ BETANCOURT, op. cit., pág. 213.
} 
Si bien se pena el cultivo compartido en el art. 368, la Audiencia Provincial de Bizcaia señala que no hay delito. Al apelar, el fiscal considera que por el número de miembros, se preveía un monto de 10 toneladas por 6 meses, lo que excluye la atipicidad de ciertos consumos compartidos. Dice el Tribunal Supremo: "El autoconsumo está excluido del radio de acción del art. 368 CP (LA LEY 3996/1995). El autoconsumo colectivo, que no deja de ser una modalidad de consumo personal acompañado, también lo está por extensión lógica y natural de aquella premisa”. Aunque cabe señalar que el art. 368 no distingue si la tenencia es para consumo o para la venta, habla de cultivo o elaboración que promueva, favorezca o facilite el consumo. Es sorprendente que un tribunal de justicia diga:

Siendo muy generalizada y estando contrastada sanitariamente la convicción de que el consumo de drogas y estupefacientes es perjudicial para la salud pública, también de las llamadas drogas blandas, se arguye que podría ser más eficaz o arrojar en conjunto más réditos que perjuicios una política de mayor tolerancia acompañada de rigurosos controles y reglamentación, huyendo del prohibicionismo absoluto.

Lo cual da a entender la existencia de juridización, tal como él la llama: "prohibicionismo", y propone entonces la normalización, que no implica ausencia de controles. También alude a "[...] la XIX Reunión Plenaria de la Conferencia de Ministerios de Justicia de los Países Iberoamericanos donde [...] se aconseja la despenalización del uso terapéutico de los derivados del cannabis con acompañamiento de una estricta regulación [...]". Inexistente en España a marzo de $2018^{38}$. El tribunal cita la decisión marco 2004/757/JAI de la Unión Europea por la que se exceptúa a los que exclusivamente realicen consumo personal. Menciona el caso de la despenalización en Uruguay y 4 (cuatro) estados de la unión americana. Señala la ley 17/1967 por la cual "Ninguna persona natural o jurídica podrá dedicarse al cultivo y producción indicados, ni aún con fines de experimentación, sin disponer de la pertinente autorización". También se hace referencia a la ley foral navarra de 2014 que cubre la distribución de cannabis entre los agrupados de una asociación. Se trata de la ley suspendida por el pleno del tribunal constitucional al admitirse el trámite de un recurso de inconstitucionalidad -que veremos más adelante-. Y se señala una resolución del Departamento de Salud de Cataluña por la que se regularizan los clubes cannábicos, y una ordenanza del ayuntamiento de San Sebastián que regula la ubicación y condiciones de ejercicio de dichos clubes. Dice que el art. 368 del CP no sanciona el consumo, pero sí toda actividad que lo promueve. Textualmente expresa el tribunal: "El cultivo para el exclusivo consumo personal es contrario a la legalidad, pero carece de relieve penal" 39 . A pesar de que se hable de "limitar el alcance del precepto punitivo" hay aquí, más que interpretación, elaboración de norma, creando el tribunal una carencia dikelógica. En tanto la ley pena a los que ejecuten actos de cultivo que faciliten el consumo. Es de creación del tribunal la distinción entre legal y punible, manifestando que puede ser ilegal el consumo de cannabis, pero no punible: "El cultivo para el exclusivo consumo personal es contrario a la legalidad, pero carece de relieve penal". Justificando la elaboración, el tribunal señala: "La desmesurada extensión ya aludida de la conducta castigada en el tipo penal [...]". Cuando en un primer momento había dicho:

\footnotetext{
38 A pesar de que el informe "Cannabis II" habla del uso terapéutico en relación a: náuseas y vómitos por tratamientos antineoplásicos, pérdida del apetito ante SIDA y cáncer terminal, tratamiento del dolor en la esclerosis múltiple, glaucoma, síndrome de Tourette, etc. DELEGACIÓN DEL GOBIERNO PARA EL PLAN NACIONAL SOBRE DROGAS, "Cannabis II. Informe de la Comisión Clínica”, Madrid, Ministerio de Sanidad y Política Social, 2009, pág. 79.

39 Se considera "[...] delictiva tan sólo la posesión de la droga con finalidad de tráfico. Sin embargo, sólo parcialmente se puede afirmar que nuestro legislador [español] no haya acogido la pretensión de las Naciones Unidas de castigar también la posesión para el consumo personal porque, si bien no se castiga penalmente, sí se sanciona administrativamente". MUÑOZ SÁNCHEZ, op. cit., pág. 36.
} 
No ignora esta Sala el debate social y también político sobre la cuestión implicada tras el asunto que se examina. No es función de un Tribunal interferir en ese debate, que sobrepasa el ámbito nacional y en el que se contraponen posiciones y se barajan argumentos en favor y en contra de soluciones que propugnan mayor tolerancia en oposición a las estrategias prohibicionistas. Menos todavía es función suya la adopción de decisiones que están en manos de otros poderes del Estado.

Puede percibirse cómo el tribunal tiene consciencia de los distintos modelos de abordaje jurídicos del cannabis. Y en una abierta asunción de tareas que son legislativas antes que judiciales, expresa: “[...] podría ser más eficaz o arrojar en conjunto más réditos que perjuicios una política de mayor tolerancia acompañada de rigurosos controles y reglamentación, huyendo del prohibicionismo absoluto". La elaboración es aún más explícita cuando el tribunal menciona los requisitos para que el autoconsumo compartido sea impune: que se trate de consumidores habituales o adictos, para evitar el favorecimiento del consumo a terceros; consumo en lugar cerrado; pocos miembros e identificables; cantidades reducidas para el consumo. Como se verá, nada de esto surge del CP español. De la frase siguiente se sigue la creación: "En realidad la doctrina de la atipicidad del consumo compartido, desarrollada por el espíritu innovador de esta Sala hace dos décadas, viene a mitigar la desmesurada amplitud que alcanzaría el tipo penal en caso de no ser interpretado en función de las necesidades estrictas de tutela del bien jurídico protegido, la salud pública" ${ }^{40}$. Es curioso que el propio tribunal desconozca la función elaboradora que cumple: "[...] no es función de la jurisprudencia (como sí lo sería de una hipotética legislación administrativa de tolerancia) establecer una especie de listado como si se tratase de los requisitos de una licencia administrativa, de forma que la concurrencia, aunque fuese formal, de esas condiciones aboque a la inoperancia del art. 368 [...]".

Como desde el CP la conducta es típica, la asociación para realizar una conducta penalmente prohibida se llama allí -como en Argentina-, asociación ilícita, y debería ser punible, pero con el recurso argumental señalado, se la declara impune. Fueron absueltos del delito de asociación ilícita, pero condenados por delito contra la salud pública en la modalidad de sustancias que no causan un grave daño a la salud.

El fallo del tribunal tiene una escala de juridización media, en tanto absuelve por asociación ilícita, con toma de consciencia de la medicalización y juridización, pero en los hechos condena por tenencia de cannabis.

Desde el punto de vista de la TGD, hay elaboración de norma, en tanto el art. 368 no prevé la atipicidad del autoconsumo, ni del consumo compartido. Y cuando el tribunal habla de cómo debe ser el autoconsumo o el consumo compartido establece requisitos como los que señala cualquier ley. Tal como lo recuerda el juez Rehnquist en la minoría del caso Roe vs. Wade, en tanto la Constitución no habla de la permisión del aborto y la Corte Suprema dividió la gestación de 9 (nueve) meses en 3 (tres) períodos de 3 (tres) meses, adjudicando derechos y obligaciones en cada uno de ellos: la permisión del aborto en el primero, la permisión del aborto en el segundo limitada a preservar la salud de la mujer, y la prohibición del aborto en el último trimestre en tanto el feto ya es viable. Otra pauta que da pie para encuadrar a este caso en el ámbito elaborador son los dichos relativos a la censura del prohibicionismo, modelo político que se dice generalmente ajeno a la consideración de los jueces. Esto tiene más de legislación judicial que de un examen de la intención de los constituyentes, como señalaba aquel juez norteamericano.

\footnotetext{
${ }^{40} \mathrm{El}$ destacado me pertenece, y da cuentas de que más que espíritu innovador hay voluntad creadora de norma.
} 
5) El 27.06.2016, la sala segunda de lo penal del Tribunal Supremo (rec. 1598/2015) se pronunció en el caso "María de Gracia Club". Trataba de Jesús María y Alexis, que fundaron la asociación cannábica María de Gracia Club, en cuyo estatuto se decía: "En estos espacios, debidamente registrados, y con obtención de las oportunas licencias municipales, se llevará a cabo, adoptando las medidas de seguridad necesarias, por profesionales altamente cualificados en biología y agronomía, y por expertas contratadas, y con total control y transparencia, y en plena colaboración con las Autoridades, el cultivo, distribución entre las socias, y consumo por éstas con fines lúdicos o medicinales o de cualquier otra índole, de plantas medicinales, especialmente de la planta Cannabis Sativa L y sus preparados o derivados, provenientes de los cultivos colectivos de la Asociación". En las inmediaciones de la sede se encontraron varios socios con marihuana, y registrado el local se encontraron euros, balanza, libros de registros, marihuana. La Audiencia Provincial de Barcelona los absuelve de los delitos contra la salud pública, ya que no se había creado riesgo para la salud de los socios ni terceros, no existiendo peligro de difusión de la marihuana. El Ministerio Fiscal apela al Tribunal Supremo, quien señala que el presente caso tiene diferencias con el pleno "Ebers": el consumo compartido no es asociación ilícita y es atípico; si se trata de personas usuarias, sin contraprestación económica y para consumo inmediato. Hay una diferencia entre los estatutos, en tanto para Ebers se permite el retiro de un acopio de cannabis para consumo particular para un período de hasta 6 (seis) meses, mientras que María de Gracia Club se limitaba a un (1) mes. En este caso, el Ministerio Fiscal no emitió un dictamen desfavorable a los fines de la inscripción de la asociación en el Registro de Asociaciones de Cataluña. El Ministerio Fiscal señalaba que del estatuto no se infiere favorecer el consumo ilegal de estupefacientes. Aun tratándose el cultivo, el mismo se constriñe a un espacio privado, para autoconsumo o investigaciones, sin perjuicio de penarse si toma contacto con terceros. El dictamen fiscal significaba la necesidad de no buscar más fuentes a los fines de indagar la licitud de la asociación. De esta manera son absueltos los acusados, debido al error de prohibición, por el dictamen fiscal. Nótese que no se habla de licitud de la conducta, sino de excusas.

El caso no es juridizador por el resultado, en tanto los acusados que integraban la asociación cannábica fueron absueltos, aunque la excusa es juridizadora, en tanto de no haber existido la registración de la asociación, sin reparos de la Fiscalía, habría habido condena. Por tal motivo lo ubico en una escala de juridización baja.

Desde el punto de vista de la TGD, el caso es elaborador, en tanto establece pautas que se diferencian de otro precedente -"Ebers"-, utilizando reglas que no se derivan de la ley.

6) El 29.06.2016, la sala segunda de lo penal del Tribunal Supremo (rec. 331/2016) se pronunció en el caso "Datura", que trataba de una asociación inscripta en el Registro Nacional de Asociaciones del Ministerio del Interior, vinculada al cannabis, para cultivo, consumo, distribución, con fines lúdicos, medicinales o de cualquier otra índole. También se hace referencia a estudios o aplicaciones culturales, científicos y terapéuticos; creación de un banco de semillas. Menciona que el socio debe respetar el consumo personal en el ámbito privado. Se podía retirar sustancia hasta un máximo de gramos (60 al mes) permitidos por persona, cuyo carnet era intransferible. Se pretendía condenar a los acusados por delito contra la salud pública, por sustancias que no causan un grave daño a la salud. Se alegaba la aplicación de la figura del error de prohibición -sobre la antijuridicidad- invencible -el autor no habría podido evitarlo- ya que fue autorizado el funcionamiento de la asociación, cuidando de que no hubiera riesgo de difusión de la droga, lesionando al bien jurídico protegido. A lo que se suma la existencia de varias asociaciones sobre el mismo tema, y fallos absolutorios de las audiencias. Una persona con una diligencia media habría incurrido en el mismo error. No se ha podido conocer la ilicitud a pesar de haber empleado su capacidad para ello. Todo lo cual llevó a la absolución. La 
autorreflexión y el conocimiento, como el asesoramiento con un experto y la jurisprudencia, son idóneos para despejar la incógnita. Lo contrario implicaría una cadena interminable de comprobaciones que impide el libre desarrollo de la personalidad. Nótese la relación con el supremo principio de justicia de Goldschmidt.

El principio supremo de la justicia consiste en que se asegura a cada cual la libertad necesaria para que se transforme de un individuo en persona, en otras palabras: para que se 'personalice'. Por ello, ninguna adjudicación debe estrechar excesivamente el ámbito de libertad del hombre; por el otro lado, el régimen debe poseer una organización que impida adjudicaciones sofocantes. El supremo principio de justicia [...] no contempla los criterios con miras a los cuales la personalización ha de llevarse a efecto. En este orden de ideas, religiones, filosofias y cosmovisiones despliegan sus influencias específicas ${ }^{41}$.

Como en el caso anterior, no hay juridización por el resultado, pero tiene una escala de juridización, en tanto hay absoluciones por el argumento de un error de prohibición, que implica que la conducta, en el fondo es ilícita o hay algún grado de reproche. De ahí que ubique a este fallo con una escala de juridización baja.

Desde el punto de vista de la TGD, el caso es aplicador, en tanto la absolución depende de la excusa del art. 14 del CP español que exime de responsabilidad criminal ante un error invencible.

7) El 5.10.2015, la sala segunda de Tribunal Supremo (rec. 755/2015) se pronunció en el caso "Three Monkeys España", asociación constituida para el cultivo, distribución y consumo de cannabis con fines lúdicos, medicinales o de cualquier otra índole. Ante una queja de los vecinos por olores, se realizó una inspección, obteniéndose hachís y marihuana. La Audiencia Provincial de Barcelona los absuelve de los delitos contra la salud pública y asociación ilícita. Menciona la ley 17/1967 según la cual el único encargado de gestionar los estupefacientes es el Estado, por lo que la actividad de la asociación encuadra en el art. 368, CP. Se alega que la falta de ánimo de lucro, o que la venta no sea indiscriminada, en nada afecta al tipo, ya que se trata de un delito de riesgo que protege la salud pública. "El objeto de protección no es el patrimonio o la capacidad económica del consumidor de estupefacientes". La asociación favorece el consumo ilegal.

Cita una decisión marco en el ámbito de la Unión Europea, y cómo ella vincula a España. Dicha decisión permite excluir de la prohibición a los consumos personales. Se penaliza toda utilización o ingesta de la droga por diversas vías orgánicas que no esté autorizada para alguna finalidad terapéutica. Dice el tribunal: "El cultivo para el exclusivo consumo personal es contrario a la legalidad, pero carece de relieve penal". Y señala como doctrina compartida que "[...] de la misma forma que el autoconsumo de droga no es típico, el consumo compartido o autoconsumo plural entre adictos no constituye una conducta penalmente sancionable [...]". Y se expresa como requisitos que se trate de consumidores habituales que se agrupan, en un lugar cerrado, para evitar la promoción, un grupo reducido, identificable, y que las cantidades sean reducidas.

El tribunal distingue el consumo personal ${ }^{42}$, del consumo atrapado por el art. $368 \mathrm{CP}$ :

\footnotetext{
${ }^{41}$ GOLDSCHMIDT, op. cit., pág. 399.

${ }^{42}$ La jurisprudencia del Tribunal Supremo español considera incluido el cannabis en el grupo de las drogas que no causan un grave daño a la salud, según el art. 368 del CP. DELEGACIÓN DEL GOBIERNO PARA EL PLAN NACIONAL SOBRE DROGAS, op. cit., pág. 75. "El Código Penal no considera delito, en ningún caso, el consumo, la posesión para el propio consumo y el cultivo de Cannabis, siempre que sea para el propio consumo del poseedor".
} 
Hay un salto cualitativo y no meramente cuantitativo, como pretende el Tribunal a quo, entre el consumo compartido entre amigos o conocidos -uno se encarga de conseguir la droga con la aportación de todos para consumirla de manera inmediata juntos, sin ostentación ni publicidad-; y la organización de una estructura metódica, institucionalizada, con vocación de permanencia y abierta a la integración sucesiva y escalonada de un número elevado de personas. Esto segundo -se capta intuitivamente- es muy diferente. Aquello es asimilable al consumo personal. Esta segunda fórmula, en absoluto. Se aproxima más a una cooperativa que a una reunión de amigos que comparte una afición perjudicial para la salud, pero tolerada. Estamos ante una actividad nada espontánea, sino preconcebida y diseñada para ponerse al servicio de un grupo que no puede considerarse 'reducido' y que permanece abierto a nuevas y sucesivas incorporaciones $^{43}$.

El consumo compartido, sin pena, excluye el almacenamiento masivo, germen del delito de peligro. El tribunal delimita entonces las actuaciones que serían permitidas en un club de cannabis. Si bien no permite el consumo ni la distribución de sustancias, sí admite actividades que podrían asimilarse a la "facilitación" o la "divulgación" o "propagación", "estimulación" o “instigación”... todo algo paradójico:

[...] la actividad desarrollada por los conocidos como clubs sociales de cannabis, asociaciones, grupos organizados o similares no será constitutiva de delito cuando consista en proporcionar información; elaborar o difundir estudios; realizar propuestas; expresar de cualquier forma opiniones sobre la materia; promover tertulias o reuniones o seminarios sobre esas cuestiones.

Lo que se pena, para el tribunal, es entonces la promoción del consumo ajeno: "La actividad que, aun siendo colectiva, [...] por ausencia de estructuras puestas al servicio del consumo de terceros, no son típicas". Daría lugar a la atipicidad: el carácter cerrado del círculo, relaciones que permiten conocerse entre sí, certeza -más allá del compromiso formal- de que el producto se destina exclusivamente al consumo individual, ausencia de espíritu comercial, espontaneidad y voluntad libre -que excluye a niños-. Ausencia de proselitismo, propaganda, captación de nuevos integrantes, publicidad, ostentación, trivialización de la conducta. Todo lo cual da lugar a la atipicidad por asimilación al propio consumo. El tribunal toma consciencia de su tarea elaboradora:

Tratándose de consumo, que no de cultivo, compartido habrá que estar a las pautas reiteradas en la jurisprudencia bien entendidas, es decir, no como requisitos sine qua non,

Íd. Nótese la contradicción con la letra del CP. Aunque varios consideran que "[...] solo es punible la posesión de drogas tóxicas, estupefacientes o sustancias psicotrópicas con la finalidad de promover, favorecer o facilitar su consumo ilegal por terceras personas". PADILLA ALBA, op. cit., pág. 69. España “[...] no da el paso demandado por la Convención de castigar las conductas orientadas al consumo personal”. MUÑOZ SÁNCHEZ, op. cit., págs. 35-36. "El núcleo de la configuración legal del delito de tráfico de drogas radica, pues, en la promoción del consumo de tales sustancias, de modo que cualquier conducta que tienda a acercar la droga a eventuales consumidores entra de lleno en la tipicidad del artículo 368, sin diferenciar entre actividades mercantiles o no". Íd., pág. 35. "Quedan incluidos dentro del tipo penal, inicialmente, todos los actos que supongan cultivo, fabricación, venta, transmisión o donación de alguna sustancia considerada como droga, así como el transporte y la mera tenencia de esa droga si se realizan con finalidad ulterior de tráfico". HERRERO ÁLVAREZ, S., "Las drogas de uso recreativo en el derecho penal español”, en "Adicciones", vol. 15, supl. "Monografía Drogas de Uso Recreativo", coord. por Julio Bobes García, y Pilar Sáiz Martínez, Palma de Mallorca, 2003, pág. 366. La claridad es mayor, según Herrero Álvarez, en tanto se elimina del texto antiguo la referencia a la "tenencia" de la droga. Íd., pág. 369.

${ }^{43}$ El resaltado me pertenece. Y justamente alude al dejo de judicializar, en tanto se cree que una conducta es mala en sí, pero se la tolera, como un acto de gracia de la autoridad estatal, como cuando se toleraba a los homosexuales, pero nadie jamás admitiría la difusión de dicha conducta o que la misma se "transmita" a través de la adopción por parte de dichos "anormales". 
sino como criterios o indicadores que orientan en la tarea de discriminar entre el autoconsumo colectivo y la facilitación del consumo a terceros.

La sentencia considera que existe un error de prohibición vencible. Ya que no hay una conducta estereotipadamente lícita socialmente. Se anula la sentencia de la Audiencia Prov. de Barcelona. Ya que

[...] el error se situaría en la percepción equivocada por parte de los acusados de que la actividad que llevaban a cabo de distribución de la droga entre sus asociados, compartiendo los gastos de cultivo e infraestructura entre todos, y con la convicción de que todos eran previamente consumidores de esa sustancia y asumían seriamente el compromiso de destinar lo recibido a su exclusivo personal consumo, estaba tolerada por el ordenamiento jurídico.

Al fundamentar la conducta de los acusados, el tribunal expresa por qué conocían de la antijuridicidad de la conducta: "La conciencia de que sopesaban y se representaron como posible la antijuridicidad de su actividad queda evidenciada por la forma en que se redactan los Estatutos de la Asociación". Se cuidan de ocultar la producción de cannabis y su distribución entre los socios previa contribución a los gastos a través de la cuota y contraprestaciones. Y la eventual creencia equivocada se hubiera despejado presentando los estatutos ante la autoridad gubernativa, con una descripción transparente de la real actividad sin esconderla bajo fórmulas ambiguas. Los acusados tenían la carga de verificar la licitud de la actividad que se proponían. El error de tipo vencible reconduce los hechos a la imprudencia, y al no haber tipo culposo de la figura de la asociación delictiva, cabe desestimar la pretensión acusatoria. Pero se los condena por delito de drogas que no causan grave daño contra la salud pública.

Hay un voto particular. Son delitos los actos de intermediación que van desde el cultivo hasta la puesta a disposición del consumidor. Pero no es delito el acto final de consumo. Aunque el tribunal reconoce que el consumo es posible si hay un acto de intermediación. No se puede aplicar la doctrina del consumo compartido, ya que deben ser adictos, para evitar la difusión del consumo. Basta que sean consumidores de fin de semana. Hay error de prohibición -creencia de estar actuando legítimamente, cuando no es así- invencible -no pudo superar el conocimiento erróneo-. Los estatutos de la asociación no son ambiguos. Se cita la realidad de las asociaciones cannábicas, contempladas en el País Vasco, en Catalunya y en Donostia. Se pueden comprar revistas temáticas. Tuvo lugar en el Senado una reunión sobre el tema. Estas asociaciones son una alternativa al mercado negro, ante la orfandad normativa. Tampoco se puede exigir otra conducta. Hay que mantener la absolución.

Coloco este fallo entre los que derivan consecuencias negativas para el consumidor, en tanto prohíbe a la asociación "Three Monkeys España", aunque delimita pretorianamente las condiciones en las cuales el consumo compartido es viable, a pesar de la prohibición del art. 368 CP. La escala de juridización es media. En los casos anteriores de error de prohibición invencible la escala era baja. Aquí hay condena penal, aunque no es alta la juridización, en tanto en alguna medida permite la conducta consumidora y asociativa, bajo ciertos recaudos. El voto disidente no es juridizador, pero a los fines del resultado que impacta en la realidad, vale la decisión de la mayoría.

Desde el punto de vista de la TGD, el caso es elaborador en tanto menciona los requisitos para que el consumo -compartido- sea atípico, cuando el art. 368 no hace dicha distinción. Aunque alude al error de prohibición. En los fundamentos es elaborador, y en la decisión es aplicador. Ante dicha disyuntiva, colocaré dicho fallo como aplicador, en tanto doy prioridad a su impacto en la vida de las personas, que fueron a la cárcel. 
8) El 17.7.2017, la sala penal del Tribunal Supremo (rec. 2417/2016) analizó la sentencia de la Audiencia Provincial de Barcelona, que condenó por el delito contra la salud pública, a raíz de la "Asociación Cultural Línea Verde BCN", constituida en Barcelona, dedicada al estudio, reflexión y divulgación en torno al uso del cannabis, no apuntando a la realización de acciones calificadas como delito por el CP. Aunque dicha asociación obtenía marihuana. Se halla en juego la aplicación de la pena del delito contra la salud pública, en la modalidad de sustancias que no causen un grave daño a la salud. Se alegaba la vulneración del derecho a la asociación. Se dice a favor de los socios: que dichas asociaciones son una realidad que ha tenido el reconocimiento de la jurisprudencia menor; el criterio de la adecuación social de la conducta; el único fin de la asociación es que los socios consuman cannabis dentro del local; la regulación de los clubes impide el predominio del mercado negro. Se trataba de una situación controlada y autogestionada de manera responsable. El producto no se difunde a terceros. Mientras que el tribunal considera que dichas asociaciones constituyen el mercado negro que pretenden eliminar. Ya que se desconoce cómo se provee la asociación de la sustancia tóxica. Hay un compromiso sin garantías de que el consumo se hará en el local. La gratuidad no elimina el carácter delictivo. La conducta enjuiciada constituye un delito a nivel internacional. Y la actividad promueve o favorece el consumo ilegal de sustancias estupefacientes. Sigue persistiendo el riesgo de lesión al bien jurídico salud de la sociedad. Más que error de prohibición hay en los acusados una actitud de indiferencia respecto a la conformidad de la asociación con el ordenamiento jurídico. La forma de redacción de los estatutos muestra que los acusados se representaban la antijuridicidad de su actividad. Ya que se cuidan de ocultar dónde produce el cannabis la asociación. El error de prohibición evitable tiene una culpabilidad disminuida, ya que hay razones para sospechar de la ilicitud de la conducta. En el caso, los estatutos son ambiguos y no había urgencia en la actuación. Y cuando hay sentencias contradictorias de tribunales de igual jerarquía, y el autor hace uso del criterio más favorable, asume el riesgo de violar la ley.

El voto particular dice que la organización articula posibilidades de consumo que excluyen la difusión a terceros. La autolesión es impune, lo que señala que la salud individual no puede protegerse o intervenirse si no media el consentimiento del individuo. Por ello es atípico el autoconsumo, si no hay riesgo de difusión a terceros. La importancia de lo dicho justifica la textualidad:

Los contornos de la libertad ${ }^{44}$ individual no se desdibujan por el hecho de que sean varios los sujetos concernidos, de tal manera que en relación al bien jurídico protegido por el artículo $368 \mathrm{CP}$, considerar el autoconsumo de varios atípico es consecuencia obligada de la atipicidad del autoconsumo de cada uno.

Lo que diferencia a Ebers de Línea Verde es que en aquella asociación los socios podían sacar la sustancia para consumirla fuera de los locales, lo que aumenta el riesgo y se incrementa la posibilidad de acopio para varios días. La mayoría del tribunal termina anulando la sentencia absolutoria, con lo cual su grado de juridización es alto. El voto disidente es muy educativo y antijuridizador, pero no determina el impacto que la decisión del tribunal tiene en la realidad de la vida.

Desde el punto de vista de la TGD, el caso es aplicador, ya que hace lo propio con el art. 368 del CP. encarcelando a los acusados, aunque es elaborador al no aplicar la figura de la asociación ilícita (art. 515) que habría correspondido. Ante esta disyuntiva, opto por priorizar la

\footnotetext{
${ }^{44}$ El destacado es mío, y apunta a mostrar la esencia del bien que es atacado por la medicalización y la juridización, en tanto ambas como intervenciones afectan la autonomía del individuo, que tal vez podría tratarse al amparo de otra disciplina científica, o de ninguna.
} 
figura de la aplicación en tanto implica cárcel para los acusados en la vida cotidiana. Nótese aquí un aspecto de la complejidad jurídica puesto de manifiesto en la contradicción que implica todo fenómeno.

9) El 3.5.2017, la Sala Penal del Tribunal Supremo (rec. 10653/2016), dicta sentencia sobre un delito contra la salud pública, ya que los acusados enviaban cocaína y hachís para su distribución a terceros. En el caso, se pretendía la atenuación de la pena, pero el tribunal expresa que ello no ocurre cuando hay habitualidad en el tráfico que acredite una dedicación profesional a la actividad delictiva. Es decir, se atenúa cuando los sujetos son los últimos eslabones de la escala delictiva o ejercen delincuencia marginal ${ }^{45}$.

Hay aquí aprovechamiento de una sustancia para el tráfico y posibilidad de que se expanda hacia aquellos que no pueden elegir libremente, como el caso de los niños. No hay juridización.

Desde el punto de vista de la TGD, el caso es aplicador, del art. $368 \mathrm{CP}$.

10) El 14.7.2010, la Sala Militar del Tribunal Supremo (rec. 132/2009), dicta sentencia contra un soldado del ejército de tierra, en tanto una resolución del Ministerio de Defensa lo sanciona separándolo del servicio por consumir drogas tóxicas, estupefacientes o sustancias psicotrópicas con habitualidad. En el caso, las muestras de orina dieron como resultado consumo de cannabis y opio. El acusado reconoce los hechos pero dice que solo consume los fines de semana. E incluso pide, si no pudiera anularse la resolución del Ministerio, que se le atenúe la sanción a una suspensión, alegando la deshabituación, los informes positivos de sus jefes, y la no afectación del servicio por los tres consumos realizados. Aquí se ve cómo el paciente también se ve incurso en la medicalización, en tanto él mismo cree estar haciendo algo malo, y pide lo que no debería. Como cuando se acepta el matrimonio homosexual pero se niega la adopción a homosexuales, porque se ve como algo malo la homosexualidad, y los niños no deberían estar con algo malo. No dar amor es algo malo. Aquí se pide la suspensión, en lugar de la no sanción, porque se piensa que el consumo de sustancias es algo malo. En este caso, no cumplir correctamente el servicio es algo malo.

En el caso, el tribunal valora la desproporcionalidad de la medida de expulsión, la falta de gravedad del hecho, las circunstancias personales del infractor (concepto de los jefes, reincidencia, número de episodios detectados, clase de droga, tratamientos seguidos, renovación o ampliación del compromiso) y el grado de afectación del servicio. El tribunal aduce los peligros que podría entrañar el consumo de drogas en la fuerza por el manejo de las armas, aunque alude que dicho consumo la desprestigiaría, lo cual es un signo de juridización. Finalmente, se baja la sanción a un año de suspensión.

\footnotetext{
${ }^{45} \mathrm{La}$ “[...] represión cae en una altísima proporción sobre los últimos eslabones de la cadena de la droga, o sea, sobre los camellos callejeros y vendedores al menudeo". MANJÓN-CABEZA OLMEDA, op. cit., pág. 223. "[...] la mayoría de las causas de drogas en Argentina del periodo analizado son por tenencia para consumo y no para comercialización [...]”. INCHAURRAGA, y MANERO, op. cit., pág. 216. Como resultado de la juridización “[...] se han calificado de complicidad hechos como el mero acompañamiento a los compradores para indicarles el domicilio de quien vendía la droga [...] la ocultación ocasional y de brevísima duración de una pequeña parte de la droga poseída por otro [...] o la ayuda prestada por quien no era dueño de la droga a otra persona poseedora de la misma para que intentase hacerla desaparecer ante la intervención policial inmediata [...]". HERRERO ALVAREZ, op. cit., pág. 367. La donación de droga es delictiva. Con una extraordinaria cantidad de requisitos, similares a los que describen las normas, el Tribunal Supremo no sanciona cuando "[...] se trata de la transmisión de dosis mínimas y gratuitamente a una persona que ya es previamente adicta a la sustancia, por parte de un familiar o persona allegada a dicho consumidor y con la intención de evitarle los sufrimientos del síndrome de abstinencia o de ayudarle a intentar una paulatina desintoxicación mediante el consumo de dosis decrecientes [...]". Íd. Piénsese en el ejercicio de desgaste intelectual que implica categorizar semejante cantidad de excusas.
} 
Cabe preguntarse entonces, desde el punto de vista de la medicalización y juridización de la salud, si el soldado no causaba perjuicios y trabajaba bien, por qué el Estado debe, no solo entrometerse en su vida, sino asignarle consecuencias negativas a su consumo, que él mismo calificaba de recreativo, al realizarlo solo los fines de semana. Suspender un año a un soldado por consumir recreativa y responsablemente drogas es nada agradable, en tanto entraña la idea de normalizar, decir qué tiene que hacer otra persona, amenazando con expulsar del trabajo y coaccionando con la suspensión. Pienso la actitud del Ministerio de Defensa español con una escala de juridización alta, ya que expresa una condena máxima del Estado hacia un individuo que solo consume una sustancia sin perjudicar a terceros, aunque la actitud del tribunal con una escala media de juridización, ya que mantiene una sanción, aunque se atenúa. Incluso se alega deshabituación, como si hubiera que salir de algo que es malo. Una advertencia podría haber configurado una juridización baja.

Desde el punto de vista de la TGD, el caso es aplicador de la ley orgánica reguladora del régimen disciplinario de las Fuerzas Armadas. No hay elaboración porque no se deja de lado la sanción, ya que aplica al menos, alguna. Sí hay determinación, en tanto, dentro del margen que prevé la norma, el tribunal precisa en el caso concreto, la sanción aplicable, atenuándola.

11) El 26.5.2011, el Tribunal Supremo, mediante sentencia recaída en el caso "Luis Manuel y Tomás", rec. 317/2010, trata la situación de 12 (doce) personas que fueron al carnaval de Badajoz y llevaban para consumir marihuana (2 gramos), cocaína (5 envoltorios; 4 gramos de pureza) y éxtasis (MDMA) (5 envoltorios; 1 gramo). Fueron detenidos por la policía porque iban a velocidad excesiva. Se dice que todos ellos eran consumidores, al menos los fines de semana y en las fiestas a las que concurrían. El tribunal dice que no hay distribución a terceros sino consumo compartido (según doctrina del 12.12.2005). Y sienta las características de la doctrina judicial, que no es la legal.

Y aquí los pobres jueces tienen que escribir en una suerte de pseudolegislación todo aquello que los políticos no se atreven a decir. Que los destinatarios del consumo son adictos o consumidores frecuentes; lo que excluye la ampliación o divulgación del consumo a otras personas; que el consumo se produce en lugar cerrado, oculto a la contemplación de terceros; cantidad insignificante, a consumirse en una sola sesión o encuentro; número reducido de consumidores, identificados, que muestra la intimidad del acto, sin trascendencia pública; previsión de consumo inmediato, para evitar alteraciones posteriores en su destino originario. Por lo cual se absuelve a los acusados. Esta sentencia no es juridizadora.

Desde el punto de vista de la TGD, el caso es elaborador, ya que se dan las

rísticas típicas del art. $368 \mathrm{CP}$. pero el tribunal no lo tiene en cuenta.

12) El 11.5.2011, la sala penal del Tribunal Supremo de España decide el caso "Luis Pedro" (rec. 2115/2010), que trataba de un empleado de supermercado que entregaba gramos de marihuana a dos consumidores. La policía encontró eso y adminículos para la preparación de dosis de cocaína. Fue condenado por tráfico de drogas por sustancias que no causan grave daño a la salud (3 años y un día de prisión, e inhabilitación para sufragar), agravada la pena por tratarse de un establecimiento público. La defensa dice que es un consumidor y que no vendía, limitándose al auto-consumo y a compartir. El tribunal tiene por probado que vendía bolsitas con marihuana, que colocaba debajo de la caja registradora y bolsitas de plástico con recortes circulares para la preparación de cocaína. Ante la atenuación por la escasa entidad del hecho y las circunstancias personales del imputado, el tribunal señala:

Se trata de dos actos de distribución clandestina de droga, ejecutados en un establecimiento público, al amparo de la mayor facilidad comisiva que permite la 
confusión entre los adquirentes de droga y los potenciales clientes del establecimiento. El hecho probado tampoco ofrece información alguna sobre cualquier circunstancia personal de Luis Pedro que pudiera debilitar el juicio de reprochabilidad (pto. 5).

Es evidente que el sistema penal se pone en marcha ante cantidades nimias, y ante personajes para nada relevantes. No obstante, no hay juridización en tanto la condena deviene justa por confundirse el ámbito privado con el público, el consumo con la venta, y la posibilidad de difundir el consumo a terceros no interesados o eventualmente inmaduros.

Desde el punto de vista de la TGD, el caso es aplicador de norma.

13) El 27.11.2012, en el caso "Carlos Jesús", rec. 348/2012, la sala penal del Tribunal Supremo condena a dos años de prisión, con las atenuantes de grave adicción y confesión. Se menciona la escasa entidad del hecho y las circunstancias personales del autor (art. 368, CP.). En un momento dice que la gravedad del injusto presenta una entidad tan nimia que lo acerca al límite de la tipicidad. Esto me recuerda a cuando alguien dice que está embarazada, pero nunca un poco embarazada. $\mathrm{O}$ no hay delito o lo hay, si la conducta encuadra típicamente. El tribunal expresa que hay escasa entidad cuando se trata de venta ocasional. Y en lo relativo a las circunstancias personales se incluye el carácter de toxicómano, los antecedentes penales, la edad de la persona, su formación intelectual y cultural, su madurez psicológica, entorno familiar y social, actividades laborales, comportamiento posterior al hecho ilícito y posibilidades de integración en el cuerpo social. Lo cual da al tipo una laxitud importante. En el caso la persona era politoxicómana, sin antecedentes penales, y entregó la sustancia a cambio de un billete. El acusado era utilizado por un narcotraficante, aprovechando su toxicomanía. El otro quemó la sustancia en un papel de plata y la aspiró. Lo cual determina la aplicación del tipo atenuado, llegando a una sanción de 9 meses de prisión con una multa de 50 euros -un par de zapatillas baratas-. Y el tribunal aclara que si no se paga devendrá una responsabilidad personal de 5 días, entiendo que de prisión.

El caso representa juridización de la salud alta, ya que envía a la cárcel a quien, podría necesitar un tratamiento de rehabilitación, si así lo decidiera voluntariamente.

Desde el punto de vista de la TGD, el caso es aplicador de norma.

\section{III.2 Fallos del Tribunal Constitucional}

1) El 7.10.2015, el Tribunal Constitucional sentó un pleno ( $\left.\mathrm{n}^{\circ} 1534 / 2015\right)$ por el que se cuestionaba la constitucionalidad de la ley de Navarra reguladora de los colectivos de usuarios de cannabis. La legislación foral busca que las personas que consumen sean ciertas y determinadas, consumidoras con anterioridad en el club, que el consumo se haga en lugar cerrado, de manera conjunta, en cantidades pequeñas, que no excedan el consumo personal, evitando que se llegue a terceros ajenos al club. El abogado del Estado señala que han aumentado las denuncias relacionadas con la marihuana. Menciona un estudio en Colorado por el que la legalización de cannabis provocó el aumento del consumo y el número de menores en tratamiento por abuso y adicción. Cita el informe EDADES por el que el $25 \%$ del consumo de marihuana es problemático, y señala los perjuicios derivados del consumo (psicosis en quienes tienen predisposición a ella; se asocia el consumo al fracaso escolar; aumento de la frecuencia cardíaca; se han encontrado asociaciones entre el consumo y trastornos mentales como depresión, ansiedad, pensamientos suicidas; y es adictiva). El tribunal agrega que no todas las denuncias culminaron en condena. Señala la exposición de motivos de la ley de Navarra en 
cuanto a que el consumo de cannabis no constituye un ilícito penal cuando es compartido y privado.

Se encamina a interpretar el art. 368 del CP. Y lo interesante del caso es cómo se evadiría la literalidad de la norma:

[...] la jurisprudencia del Tribunal Supremo entiende que la promoción, favorecimiento o facilitación afecta a la salud pública como bien jurídico tutelado en tanto que tales conductas se sitúan en una cadena de tráfico o de favorecimiento mediante una difusión indiscriminada de las sustancias prohibidas hacia destinatarios indeterminados. Por ello, cuando quede excluido el riesgo típico para la salud pública porque no exista posibilidad de difusión, de facilitación o de promoción del consumo por terceras personas indeterminadas o indiscriminadamente, aquellas conductas, que no despliegan peligro para la salud de terceros, son consideradas penalmente atípicas.

Si se lee bien lo que el tribunal señala, el CP no requiere que se ponga en peligro por difusión o se creen riesgos para la salud, sino simplemente, que se den las conductas que enumera. Se habla de "conductas penalmente inocuas", pero son conductas penales al fin, en el sentido de típicas. También se alude a un cambio de norma cuando señala que el consumo compartido es atípico si se circunscribe a un grupo reducido e identificado. De hecho, el tribunal toma consciencia de ello cuando dice: "[...] la regulación de los clubes de consumidores de cannabis contenida en la Ley navarra ampara conductas que no permiten descartar la posibilidad de que resulten penalmente relevantes y subsumibles en la previsión típica del art. 368 CP [...]”. Para finalmente descartar la viabilidad constitucional de la norma ya que las asociaciones podrían dar lugar a las acciones penales enumeradas en el art. 368, teniendo la ley autonómica un impacto negativo en la salubridad y seguridad públicas, ya que luego esas conductas serían calificadas como infracciones penales.

La decisión del tribunal significó la suspensión de la ley foral de Navarra. Lo que implica un grado de juridización alto, en tanto impide la libre asociación para una actividad que solo involucra a los que voluntariamente deciden adscribirse a ella.

Desde el punto de vista de la TGD, el caso es elaborador en sus fundamentos, pero aplicador en su decisión concreta. Priorizo el impacto de la decisión en la vida cotidiana, por lo que lo considero finalmente aplicador.

2) En fecha 9.5.2017 el Tribunal Constitucional decide (rec. 231/2017) mantener la suspensión de la ley vasca referida a las asociaciones cannábicas. El gobierno vasco alega que existen muchos clubes de cannabis que se encuentran registrados, actuando conforme a la doctrina del tribunal supremo sobre el consumo compartido. Todo lo cual controla y protege más. Se alega una diferencia con la ley navarra en tanto ésta autoriza el retiro de marihuana, lo que da lugar a la relevancia a los fines de la aplicación del art. $368 \mathrm{CP}$. El abogado del Estado señala que la ley vasca va contra el CP., lo que afecta la seguridad jurídica. Menciona un estudio encargado por la Delegación del Gobierno para el Plan Nacional sobre Drogas de la entidad EDADES -señalado en el caso anterior- que tiene una valoración negativa hacia la marihuana.

El Tribunal recuerda la doctrina del consumo compartido, que no es penalmente relevante cuando hay un grupo reducido de adictos, identificables o determinados. La ley vasca permite que se den las conductas subsumibles en el art. $368 \mathrm{CP}$. Lo que ocasionaría un perjuicio irreversible en los intereses públicos. Hay aquí un alto nivel de juridización. 
En la ley vasca se hace referencia al objetivo de la reducción de daños a través de la regulación de las asociaciones cannábicas que promoverán la prevención de las adicciones y la promoción de un consumo responsable. Nótese cómo aquí no hay juridización ni medicalización en tanto se apunta a un consumo libremente decidido, pero responsable, en tanto no perjudique al individuo, ni a los demás. Por ello la ley dice que ingresarán solo los mayores de edad.

Desde el punto de vista de la TGD, el caso es aplicador.

\section{DISCUSIÓN. JURIDIZACIÓN DE LA SALUD}

Plantearemos aquí el análisis de los fallos tratados, organizándolos según su bajo, medio o alto nivel de juridización, en este caso judicial, ya que la intromisión indebida del Derecho proviene de la judicatura.

Podría considerarse que hablar de error de prohibición vencible o invencible sería una gracia del Estado para con la población, cuando en verdad, no cabría hablar de error, ya que vivir de acuerdo a lo que cada uno considere lo mejor (o peor) para sí no constituye un "error” sino el ejercicio de la libertad. De hecho el suicidio no es un error, sino un acto de libertad, que alude al fin de la existencia de la persona, que decide partir. Nada somos si no podemos ejercer, desarrollar o dejar de hacer lo que nos constituye como personas, que es nuestra posibilidad de elegir. Ya lo decía Kant: "una acción es conforme a derecho (recht) cuando permite, o cuya máxima permite a la libertad del arbitrio de cada uno coexistir con la libertad de todos según una ley universal" ${ }^{\prime 4}$. En efecto, una reforma al CP implicaría dejar de ver la protección de la salud pública y pasar a proteger la libertad del consumidor ${ }^{48}$ como bien jurídico. Ser humano es ser capaz de elegir los propios fines ${ }^{49}$.

En función de los casos que tratamos, Robert Alexy caracteriza el principio de proporcionalidad que hay que ejercer a la hora de abordar un caso, señalando que "una oposición puede ser mejorada sin detrimento de la otra" $"$. Lo que en nuestro caso significaría que puede dejarse que los individuos se reúnan, y consuman cannabis, solos o en reuniones o asociaciones, con los debidos recaudos, a la vez que se protege a la población en la seguridad de su salud (pública). En este trabajo vimos que el Tribunal Supremo no trata de la misma manera a todos los clubes cannábicos. La idea es "[...] que de dos medios [...] que son, a grandes rasgos igualmente idóneos, aquel que interfiere menos intensamente [...] debe ser elegido" ${ }^{\text {. }}$. Nótese la similitud con mi concepto de "juridización", que implica la intromisión del Estado en la esfera individual ${ }^{52}$. ¿De qué manera puede llegarse a la protección de los niños, de la

\footnotetext{
${ }^{46}$ Sobre el tema Morin señala: "[...] no significa un error sino el hallazgo de una capa profunda de la realidad que, justamente porque es profunda, no puede ser traducida a nuestra lógica”. MORIN, CIURANA, y MOTTA, op. cit., pág. 41.

${ }^{47}$ KANT, I., "La metafísica de las costumbres", trad. de Adela Cortina Orts y Jesús Conill Sancho, Barcelona, Altaya, 1993, pág. 39.

${ }^{48}$ PADILLA ALBA, op. cit., pág. 10. "[...] solo las drogas que producen dependencia física (p. ej. heroína) afectan a la libertad [...]”. Íd., pág. 58. "[...] la criminalización del consumo se opone frontalmente a la libertad personal que debe quedar inaccesible al Derecho Penal”. MANJÓN-CABEZA OLMEDA, op. cit., pág. 227.

${ }^{49}$ LÓPEZ BETANCOURT, op. cit., pág. 194.

50 ALEXY, R., “¿Cómo proteger los derechos humanos? Proporcionalidad y racionalidad”, en AAVV, "Argumentación, derechos humanos y justicia", coord. por Juan Pablo Alonso y Renato Rabbi-Baldi Cabanillas, Bs. As., Astrea, 2017, pág. 29.

${ }^{51}$ Íd., pág. 30.

52 “[...] las consecuencias de la dependencia han sido exageradas erróneamente en el medio jurídico y político [...]”. LÓPEZ BETANCOURT, op. cit., pág. 191.
} 
población no fumadora, y para visibilizar y controlar el consumo, sin llegar a afectar la libertad personal? Extremando los recaudos y controles hacia los clubes de cannabis. De esta forma, el control no será desproporcionado. De ahí que sea desaconsejable emplear la figura del delito de peligro abstracto, en tanto es desproporcionado pensar que la mera tenencia justifique una intromisión semejante del Estado, en tanto el consumo individual o compartido, pero privado, no se extiende más allá de las fronteras de la intimidad. Nadie se entera más que los interesados. Según el caso "Arriola", por el que la Corte Suprema de Justicia de la Nación argentina admite el consumo personal privado, respetando la privacidad, allí se hace alusión al principio de reserva, por el cual la Constitución señala que "Las acciones privadas de los hombres que de ningún modo ofendan al orden y a la moral pública, ni perjudiquen a un tercero, están sólo reservadas a Dios, y exentas de la autoridad de los magistrados" (art. 19). En efecto, "[...] la penalización del tráfico de sustancias como el cannabis y sus derivados no estaría protegiendo la

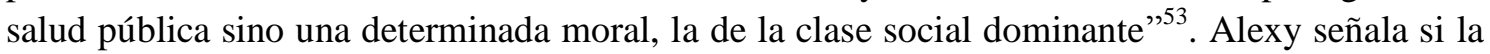
Constitución excluye el propósito perseguido por el legislador, a fin de evaluar la proporcionalidad de la interferencia con el derecho fundamental ${ }^{54}$. Piénsese en los perjuicios que acarrea el tabaco, en relación con el cannabis, a pesar de lo cual se permite aquel con una mera imposición de colocar leyendas alusivas a la salud en los envases ${ }^{55}$. Una prohibición total del producto sería una interferencia grave, una moderada sería prohibir máquinas expendedoras de cigarrillos, y restricciones de ventas en tiendas seleccionadas, mientras que la etiqueta sería una prohibición moderada ${ }^{56}$. Una restricción moderada a la venta del cannabis podría ser conseguirlo solo en farmacias, como ocurre en Uruguay, en clubes con restricciones a los socios para el ingreso, etc. Si se sigue la línea argumental, y si el bien jurídico tutelado es la salud pública, no debería afectarse ni la libertad individual, ni el ámbito en el que ella se ejerce, que si es individual debe ser el privado, y en el cual solo dispone el individuo. Y si es un problema sanitario, no deben mezclarse las concepciones de moralidad de la población o de ciertas instituciones, sean políticas o religiosas. Por otra parte, una ley no puede regular sino situaciones colectivas, y no a la persona en su individualidad ${ }^{57}$.

[...] si se considera que el único bien jurídico protegido en el delito de tráfico ilegal de drogas es la salud pública, quedaría perfectamente justificada la incriminación de las llamadas drogas duras (en la terminología del Código Penal 'sustancias o productos que causen grave daño a la salud': opiáceos, alucinógenos, anfetaminas, etc.) pero no la de las drogas blandas ('los demás casos': básicamente el cannabis y sus derivados), cuya prohibición, en la medida en que se trata de sustancias que realmente no poseen virtualidad práctica alguna para lesionar el bien jurídico salud pública, podría suponer un abuso por parte del legislador de los recursos del Derecho Penal ${ }^{58}$.

\footnotetext{
${ }^{53}$ PADILLA ALBA, op. cit., pág. 36. España tiene como finalidad "[...] disminuir de forma significativa el consumo de drogas y prevenir al máximo el impacto sanitario y social de los diversos problemas y daños relacionados con los mismos". DELEGACIÓN DEL GOBIERNO PARA EL PLAN NACIONAL SOBRE DROGAS, op. cit., pág. 12. No puede usarse el poder el Estado, y bajo el ropaje de la democracia, constituida por el voto de ciudadanos libres e iguales, para imponer ideales de vida. LÓPEZ BETANCOURT, op. cit., pág. 213. "[...] hubo un tufo a moralina y un trasfondo puritano, entendiendo puritanisno en su peor acepción, o sea, como miedo a que otro sea feliz". MANJÓNCABEZA OLMEDA, op. cit., pág. 46. Como muchas drogas psicoactivas van contra lo normal, que apunta a una persona lúcida lista para producir, adaptada al sistema económico capitalista, pueden afectar al fundamento filosófico, religioso y político de dicho sistema, que es la ética protestante.

${ }^{54}$ ALEXY, op. cit., págs. 35-36.

55 “[...] la contradicción entre la legalización del alcohol y la incriminación de determinadas sustancias no gravemente nocivas representa un aspecto concreto de esta lucha de morales”. PADILLA ALBA, op. cit., pág. 36.

${ }^{56}$ ALEXY, op. cit., pág. 40.

${ }^{57}$ PADILLA ALBA, op. cit., pág. 32.

${ }^{58}$ Id., pág. 35.
} 
Cuando el autor se refiere al abuso, evidentemente está haciendo alusión implícita a la juridización de la salud, en este caso, legislativa. En suma, el cannabis es una planta y “[...] un desencadenamiento de comportamientos agresivos, pueda deberse a condiciones y características previas del consumidor, y no al simple hecho del uso de la sustancia" ${ }^{~} 59$. El Estado no puede prohibir una planta o su consumo, sino todos aquellos comportamientos riesgosos que ocasionan un daño, o su posibilidad real, a terceros ${ }^{60}$. También es altamente arbitraria la consideración de la cantidad que se considera para consumo propio y que, por ende, se estima fuera de la penalidad. En suma, si un fenómeno complejo habla de varias dimensiones, aspectos, aristas que abarca, el cannabis podría enmarcarse en el uso, consumo recreativo, abuso, consumo problemático, dependencia, adicción, intoxicación ${ }^{61}$.

Cabe dejar a salvo algunos votos particulares de algunas sentencias, que dan cuenta de la juridización en la que incurre el Estado. Piénsese que las minorías de hoy pueden ser las mayorías de mañana.

En este trabajo se analizaron 15 sentencias españolas: 13 de ellas del Tribunal Supremo, y 2 de ellas del Tribunal Constitucional. Las sentencias que se encabezan con la letra "c" corresponden al Tribunal Supremo y las "d" al Tribunal Constitucional. El número que sigue es el de la identificación correlativa. Luego le sigue el número de recurso en el tribunal en cuestión, ya que viene en recurso de decisiones de tribunales funcionalmente inferiores. Hay 5 casos de juridización alta, que se dan en las resoluciones: c-3-2010 (rec. 397/2010); c-8-2017 (rec. 2417/2016); d-1-2015 (rec. 1534-2015); d-2-2017 (rec. 231-2017); y c-13-2012 (rec. 3482012). Hay 3 casos de juridización media: c-4-2015 (rec. 1765-2014); c-10-2010 (rec. 1322009); y c-7-2015 (rec. 755-2015). Y hay 2 casos de juridización baja: c-5-2016 (rec. 15982015) y c-6-2016 (rec. 331-2016). En tanto hay ausencia de juridización en 5 casos: c-1-2008 (rec. 528-2007); c-2-2007 (rec. 1667-2006); c-9-2017 (rec. 10653-2016); c-11-2011 (rec. 3172010); y c-12-2011 (rec. 2115-2010). Esto muestra que hay más juridización que ausencia de juridización, si se confrontan 10 contra 5 . En el ámbito de la juridización, prevalece la alta, con 5 casos, por sobre la media con 3 y la baja con 2.

Haciendo un análisis de TGD, sobre un total de 15 sentencias, 4 fallos crean normas, en tanto van más allá de los límites de ella, y 11 resoluciones aplican la norma. Lo que revela un escaso protagonismo del Poder Judicial superior español a la hora de relacionarse con los poderes partidarios del Estado. Sí hay un acompañamiento de la política de juridización de la salud en relación al cannabis. Lo que en alguna medida explica que aún España, a nivel nacional, no tenga, al menos, un uso permitido del cannabis para fines medicinales o científicos, como sí ocurre en Argentina con la ley 27350 a nivel nacional y la ley 13602 de la Provincia de Santa Fe.

Nótese que en tanto el caso no revela juridización, desde el punto de vista bioético, es elaborador de norma, desde el punto de vista jurídico. Es decir, salvar la salud y la libertad del individuo, en los tribunales superiores españoles, implica mayor protagonismo de ellos, creando normas. Aunque no todo caso aplicador supone juridización, ya que vimos que es justa la aplicación de una pena cuando hay exhibición del consumo o se trafica con la marihuana u otra droga, ya que se trasciende el ámbito privado.

\footnotetext{
${ }^{59}$ LÓPEZ BETANCOURT, op. cit., pág. 205. "En relación con el cannabis se debe de partir de que el consumo autocontrolado es perfectamente posible y es una realidad para la mayor parte de los consumidores. La mayor parte del consumo de cannabis es por razones lúdicas, sociales o rituales y no responde a razones de inevitabilidad y, por tanto, no es un consumo problemático". MUÑOZ SÁNCHEZ, op. cit., pág. 39.

${ }^{60}$ Íd., pág. 213.

${ }^{61}$ V. OMS, “Glosario...”, op. cit.
} 


\section{CONCLUSIÓN}

La conducta de los tribunales españoles de alta instancia es en general de juridización, en tanto, por ejemplo, no permite la libre asociación de ciudadanos a los fines de su instrucción, perfeccionamiento, y consumo saludable de cannabis, prohibiendo dicha asociación. La juridización implica seguir la inercia prohibicionista, el consenso internacional que se ha vuelto sagrado, repitiendo la lección aprendida ${ }^{62}$ de la lucha contra las drogas, por un mundo libre de drogas, y la demonización de la marihuana, como si fuera una droga cualquiera, como las duras.

El trabajo reveló también cómo al analizar algunos fallos, se mostraba el carácter complejo del Derecho, visto en la característica de los aspectos contradictorios que revelaban, ya que algunos no aplicaban la figura de la asociación ilícita, con la mayor pena que ello implicaría, pero dejaban una sanción por encuadrar el caso en el delito simple de drogas del art. $368 \mathrm{CP}$. Son en este sentido más aplicadores que elaboradores de normas, con toda la falta de protagonismo que ello implica en el concierto de los poderes del Estado.

Nótese que el Poder Judicial siempre ha sido el guardián de los derechos de las minorías, de la libertad de los individuos, de ahí que la carencia dikelógica, es decir, declarar una norma como injusta, sea la herramienta para la salvaguarda de la libertad. En nuestro tema, la intervención del Estado en la vida de los individuos toma variadas formas, en este caso la del Derecho en el consumo de cannabis, en la rama de los tribunales superiores españoles. Resta la comparación con Argentina, pero parece que España sigue el compás de la juridización.

\section{BIBLIOGRAFÍA}

- AleXY, R., “¿Cómo proteger los derechos humanos? Proporcionalidad y racionalidad”, en AAVV, Argumentación, derechos humanos y justicia, coord. por Juan Pablo Alonso y Renato Rabbi-Baldi Cabanillas, Bs. As., Astrea, 2017, págs. 25-48.

- ARAna, X., Drogas, legislaciones y alternativas. De los discursos de las sentencias sobre el tráfico ilegal de drogas a la necesidad de políticas diferentes, Donostia/San Sebastián, Tercera Prensa, 2012.

- CARrIER, N., Y QUIRION, B., "Les logiques de contrôle de l'usage des drogues illicites : La réduction des méfaits et l'efficience du langage de la péllirisation", en Drogues, santé et société, vol. 2, nº1, Montréal, 2003, págs. 4-34.

- Couso Salas, J., "El uso de precedentes en materia penal: retórica y realidad en perspectiva", en Revista General de Derecho Penal, Madrid, Iustel, RI405151, págs. 1-47.

- Delegación del Gobierno Para el Plan Nacional sobre Drogas, Cannabis II, Madrid, Ministerio de Sanidad y Política Social, 2009.

- FRANK, J., "Una defensa de las escuelas de abogados", en AAVV, Enseñanza clínica del Derecho. Una alternativa a los métodos tradicionales de formación de abogados, coord. por Marta Villarroel y Christian Courtis, México DF, Instituto Tecnológico Autónomo de México, 2007, págs. 57-90.

\footnotetext{
${ }^{62}$ LÓPEZ BETANCOURT, op. cit., pág. 179.
} 
- Galati, E., "Introducción al pensamiento jurídico complejo. La teoría trialista del mundo jurídico y el pensamiento complejo de Edgar Morin", en Revista de la Facultad de Derecho, n²0, Rosario, UNR, 2012, págs. 157-215.

- Galati, E., "La costumbre en el Derecho Argentino. Análisis jusfilosófico y trialista de la 'razón' del pueblo", Ciudad Autónoma de Buenos Aires, Teseo-Universidad Abierta Interamericana, 2015, https://elvioacademia.files.wordpress.com/2016/11/galati-lacostumbre-en-el-derecho-argentino.pdf (23.3.2018).

- Galati, E., "Los comités hospitalarios de bioética. Una comprensión trialista y transdisciplinaria desde el Derecho de la Salud", Ciudad Autónoma de Buenos Aires, Teseo-Universidad Abierta Interamericana, 2015, https://elvioacademia.files.wordpress.com/2016/11/galati-los-comitc3a9s-hospitalarios-debioc3a9tica-transdisciplinariedad.pdf (23.3.2018).

- Goldschmidt, W., Introducción filosófica al Derecho. La teoría trialista del mundo jurídico y sus horizontes, $6^{\mathrm{a}}$ ed., Bs. As., Depalma, 1987.

- Herrero Álvarez, S., "Las drogas de uso recreativo en el derecho penal español", en Adicciones, vol. 15, supl. "Monografía Drogas de Uso Recreativo", coord. por Julio Bobes García, y Pilar Sáiz Martínez, Palma de Mallorca, 2003, págs. 361-383.

- Holmes, O., "The path of law", en Harvard Law Review, 10, 1897.

- ILlich, I., Némesis médica. La expropiación de la salud, Barcelona, Barral, 1975.

- InChaurRagA, S., "Marihuana; el argumento más débil de la teoría prohibicionista", en AAVV, Las drogas: entre el fracaso y los daños de la prohibición. Nuevas perspectivas en el debate despenalización/legalización, comp. por Silvia Inchaurraga, Rosario, Centro de Estudios Avanzados en Drogodependencias y SIDA, Asoc. De Reducción de Daños de la Argentina, 2003, págs. 203-231.

- Inchaurraga, Y Manero, E., "Políticas de drogas, alteridades y construcción de la ciudadanía en Argentina contemporánea”, en Outros Tempos, vol. 14, n²4, 2017, págs. 207-227.

- KANT, I., La metafísica de las costumbres, trad. de Adela Cortina Orts y Jesús Conill Sancho, Barcelona, Altaya, 1993.

- Leary, W. E., Marijuana. Aspectos sociales, jurídicos y económicos de la obtención de enteógenos cannabinoides y alternativas a la actual política criminal en España, Londres, Amazon, 2012.

- LÓPez Betancourt, E., Drogas, entre el derecho y el drama, Madrid, Centro de Estudios Ramón Aceres, 2011.

- Manjón-CABeza Olmeda, A., La solución. La legalización de las drogas, Barcelona, Random House Mondadori, 2012

- Morin, E., CiUrana, R., Y MotTA, R., Educar en la era planetaria. El pensamiento complejo como método de aprendizaje en el error y la incertidumbre humana, Valladolid, UNESCO - Univ. de Valladolid, 2002.

- Morin, y Piatelli-Palmarini, M., "La unidad del hombre como fundamento y aproximación interdisciplinaria", en AAVV, Interdisciplinariedad y Ciencias Humanas, trad. de Jesús Gabriel Pérez Martín, Madrid, Tecnos, 1983, págs. 188-212.

- MuÑoz SÁNCHEZ, J., "Política criminal de drogas. Reflexiones en torno a la normalización del cannabis", en AAVV, Hablemos del cannabis. Avances en drogodependencias, ed. por L. Pantoja, Bilbao, Universidad de Deusto, 2007, pág. 31-43. 
- Organización Mundial de la SAlud, Glosario de términos de alcohol y drogas, Madrid, OMS y Gobierno de España, 1994.

- Padilla Alba, H., La problemática de legalizar el cannabis en España, Córdoba, Universidad de Córdoba, 2011.

- Soler, S., Derecho Penal Argentino, T. 2, actualizado por Guillermo Fierro, Bs. As., TEA, 1992.

- Zaffaroni, E., Manual de Derecho Penal. Parte General, 6ª ed., Bs. As., Ediar, 1997. 